\title{
A OBRA EM PÉ DE PÁGINA: AS NOTAS DE RODAPÉ NOS LIVROS INDIGENISTAS DE JOSÉ DE ALENCAR
}

\author{
THE WORK ON A FOOTNOTE: FOOTNOTES ON THE \\ BOOKS ABOUT INDIGENOUS PEOPLES BY JOSÉ DE \\ ALENCAR
}

\author{
Daniela Casoni Moscato* \\ Cláudio DeNipoti**
}

\begin{abstract}
Resumo: Este artigo procura compreender a nota de rodapé como elemento constituinte da obra de José de Alencar, no sentido de que as construções discursivas contidas nas notas de rodapé fornecem indícios sobre as leituras realizadas pelo autor, ao mesmo tempo que procuram legitimar, na historiografia que antecede o romance, as ideias sobre natureza, indígenas e nacionalidade que este autor constrói em sua obra literária - especialmente as do chamado "ciclo indigenista". As notas de rodapé, vistas em conjunção com outros elementos não ficcionais - os paratextos - da obra alencariana, permitem acessar a construção das ideias pertinentes à sua literatura. Ao mesmo tempo, permitem um acesso particular ao mundo da leitura no passado ao identificar práticas de leitura e as apropriações que Alencar fez de textos e ideias.
\end{abstract}

Palavras-chave: História da leitura. José de Alencar. Notas de rodapé.

Abstract: This article tries to understand the footnote as a part of the literary work of José de Alencar, meaning it will see the discursive structures within the footnotes in order to gather clues about the writer's readings, while, at the same time, to see how the footnotes functioned as a means of legitimation, in earlier Brazilian historiography, the ideas of nature, indigenous peoples and nationality which this author built in his literature, particularly those works of the "indigenous cycle". The footnotes, seen with other non fictional elements of Alencar's books, allow us to access how the ideas we find in his romances was "built". Simultaneously, it allows us a particular entrance to the world of reading in the past, as it identifies reading practices and appropriations this author had.

Keywords: Reading history. José de Alencar. Footnotes.

\footnotetext{
* Doutoranda no Programa de Pós-Graduação em História da Universidade Federal do Paraná (UFPR). Bolsista da CAPES. E-mail: historiar7@gmail.com

** Professor na Universidade Estadual de Ponta Grossa (UEPG). E-mail: cnipoti@uepg.br
} 
Como o banheiro, a nota de rodapé moderna é essencial à vida histórica civilizada; como o banheiro, ela parece ser um assunto entediante para a conversação polida $\mathrm{e}$ chama a atenção, na maioria das vezes, quando funcional mal. Como o banheiro, a nota de rodapé permite lidar privadamente com tarefas feias; como o banheiro, as notas de rodapé descem suavemente pela tubulação - muitas vezes, recentemente, nem mesmo no pé da página, mas no fim do livro. Fora da vista, e até mesmo fora das reflexões, parecem ser exatamente o lugar a que um dispositivo tão banal deva pertence. ${ }^{1}$

A história da palavra impressa - também chamada "história do livro" ou "história da leitura", ao longo das últimas décadas - tem, dentre seus vários pressupostos teóricos comuns à prática historiográfica recente, a possibilidade de se aperceber de elementos do texto que, tradicionalmente não compunham a "essência" da obra colocada à leitura. Assim, estudos sobre a produção e recepção da palavra impressa no passado, voltados essencialmente para a constituição de práticas culturais relacionadas ao $\operatorname{livro}^{2}$, tem sido realizados nesse "campo" de conhecimento. Um exemplo são os estudos de elementos não estruturais de obras impressas, como as dedicatórias, que agem mais como recurso retórico de ordenação social do que como parte do texto (embora devam fazer parte da leitura). ${ }^{3}$ As notas de rodapé tem sido, nesta mesma ideia, um importante elemento de reconstituição de práticas de leitura no passado, especialmente ao considerarmos a já longamente discutida dificuldade de recuperarmos os "como" e "por que" da leitura. ${ }^{4}$

O uso moderno das notas de rodapé identifica-se com o surgimento da erudição - em especial na prática da escrita da história - do século XVIII, criando, inicialmente "o equivalente da civilização industrializada para a antiga evocação da Musa: uma longa nota na qual o autor agradece a professores, amigos e colegas [evocando] uma confraria da República das Letras - ou, ao menos, um grupo acadêmico de apoio - reivindicada pelo escritor". ${ }^{5}$ Tendo nascido sob a égide da ciência e da erudição modernas, ao longo do século XIX, acreditava-se que a função das notas de rodapé era mais evidente, em especial para os historiadores: "o texto convence, as notas provam". ${ }^{6}$ Porém, suas funções são, desde então, mais amplas:

Em primeiro lugar, elas convencem [...] o leitor de que o historiador realizou uma quantidade aceitável de trabalho, o suficiente para mentir dentro dos limites toleráveis do campo. Como os diplomas na parede do dentista, as notas comprovam que os historiadores são praticantes "bons o 
bastante" para ser consultados e recomendados [...] Em segundo lugar, indicam as principais fontes que o historiador realmente usou. ${ }^{7}$

Sendo então uma presença constante na escrita ocidental desde a expansão europeia dos textos, a partir de meados do século XVIII, ganhando força ao longo do século XIX com a industrialização da produção editorial e a internacionalização do romance", as notas de rodapé servem para "mostrar que a obra que sustentam reivindica autoridade e solidez com base nas condições históricas de sua criação", que:

[...] seu autor cavoucou suas fundações e descobriu seus componentes nos lugares certos e usou os artifícios corretos para juntá-los. Para fazê-lo, localizam a produção da obra em questão no tempo e no espaço, enfatizando os horizontes e as oportunidades limitados de seu autor, e não os de seu leitor. ${ }^{9}$

As notas de rodapé são aqui pensadas, portanto, como "paratextos", ou seja, textos adicionais à obra - ou textos não ficcionais que fazem parte de obras literárias, como prefácios, posfácios, cartas ao leitor, pós-escritos, etc. Este artigo vai buscar, na obra de José de Alencar, os paratextos - em especial as notas de rodapé - que permitam analisar as bases da leitura (e da escrita) da obra literária deste autor, tentando rastrear o processo "criador" do sujeito, ou seja, onde Alencar encontrou e como se apropriou dos elementos que o auxiliaram na construção da representação indígena contida em sua obra literária.

Para este estudo a principal fonte são as notas do romance $O$ guarani, cotejado com outras obras do autor, em especial as também "indigenistas" Iracema e Ubirajá - e também outros paratextos como o Posfácio à $2^{\circ}$ edição de Iracema (1870) e o prefácio Bênção Paterna da obra Sonhos D'Ouro (1872) que confirmam as questões abordadas por Grafton, incluindo ai a defesa de posições, evocações de polêmicas e a apresentação de um conhecimento historiográfico. ${ }^{10}$ Com esses elementos, este estudo busca apreender as leituras feitas por José de Alencar e como essas leituras podem ter influenciado o ideário nacionalista, romântico e racionalista que este autor construiu em seus romances históricos.

De um dos cabeços da Serra dos Órgãos desliza um fio d'água que se dirige para o norte, e engrossando com os mananciais, que recebe no seu curso de dez léguas, tornase rio caudal.

É o Paquequer: saltando de cascata em cascata, enroscandose como uma serpente, vai depois se espreguiçar na várzea e embeber no Paraíba, que rola majestosamente em seu vasto leito. ${ }^{11}$ 
A descrição acima inicia a primeira parte, intitulada Os Aventureiros, do livro $O$ Guarani de José de Alencar. Primeira narrativa indigenista de Alencar, que o consagrou como autor nacionalista, o romance foi publicado, inicialmente, em folhetins no Diário do Rio de Janeiro, entre janeiro e abril de 1857 e, ainda no mesmo ano, em uma primeira edição em quatro fascículos (reunidos em um só volume a partir da segunda edição). O trecho acima, ao descrever a Serra dos Órgãos e o rio Paquequer, apresenta a "majestosa" natureza brasileira como cenário da intriga desenvolvida posteriormente no romance. Intitulado Cenário, o primeiro capítulo da obra, ao narrar a paisagem brasileira, já apresenta uma nota de rodapé:

O Paquequer: Para se conhecer a exatidão dessa descrição do rio Paquequer naquela época, leia-se B. da Silva Lisboa, Anais do Rio Janeiro, $1^{\circ}$ tomo, pág. 162. Hoje as grandes plantações de café transformaram inteiramente aquêles lugares outrora virgens e desertos. ${ }^{12}$

Essa não foi a única nota do romance. O Guarani contém cinquenta e nove notas de rodapé. Dessas, vinte e duas apresentam descrições e costumes indígenas, vinte e seis descrevem a fauna e a flora e, as onze restantes dedicamse a personagens históricos. Observamos também que vinte e três não oferecem nenhuma menção a autores ou obras e as demais trinta e seis exibem referências bibliográficas que podem variar entre obra ou autor e, em alguns momentos, ambos. Nessas trinta e seis notas, incluem-se anais, crônicas coloniais, tratados médicos, relatos de viajantes, e estudos históricos que apoiam três elementos da obra: o índio, a paisagem e os personagens históricos. Em relação aos dois primeiros elementos, temos vinte e uma notas que trazem alguma referência acerca dos autores que foram lidos por Alencar:

Padre Gumilha, Orenoco Ilustrado - 1 nota;

J. J. Lisboa, não consta a obra - 1 nota;

Simão de Vasconcelos e Lamartinière, não consta a obra - 1 nota;

Auguste de Saint-Hilaire, não consta a obra - 1 nota;

Francisco Adolpho de Varnhagen, História Geral do Brasil - 1 nota

Manoel Aires de Casal, Corografia Brasílica - 2 notas;

Frei José Mariano da Conceição Veloso, Flora Fluminense - 2 notas;

Baltasar da Silva Lisboa, Anais do Rio de Janeiro I tomo - 2 notas;

Alexander von Humboldt \& Dr. José Francisco Xavier Sigaud,

Du Climat et les Maladies du Brésil - 3 notas;

Gabriel Soares de Sousa, Roteiro do Brasil - 9 notas.

Essa seleção evidencia muito mais que os autores lidos e, provavelmente, utilizados por Alencar no processo de construção de sua obra, pois traduz o que 
foi essencial para ele como leitor, deixando-nos pistas do "que" leu e "como leu" todo esse acervo disponível em sua época. Robert Darnton já demonstrou como um pequeno catálogo ou uma pequena listagem de uma biblioteca particular pode "servir como um perfil do leitor, ainda que não tenhamos lido todos os livros que nos pertencem e tenhamos lido muitos livros que nunca adquirimos". ${ }^{13}$ No caso de Alencar, não contamos com sua biblioteca privada, mas, por outro lado, temos várias citações de suas possíveis leituras que, além de autores e títulos, revelam um modo de ler as fontes utilizadas por Alencar em $O$ Guarani. Entre citações, títulos e páginas, Alencar seleciona temas, costumes e descrições. Em alguns momentos, comenta suas leituras, opina e registra essa prática cultural.

Observando as notas referentes ao indígena e seus costumes, podemos organizá-las da seguinte forma: nove notas não apresentam autor; quatro fazem referência à Gabriel Soares de Sousa; a Humboldt e ao Dr. Sigaud são indicadas duas notas para cada um; e para Varnhagen, Aires de Casal, Simão de Vasconcelos, Lamartinière e Gumilha uma nota cada. A utilização de notas de pé de página não se restringe apenas a $O$ Guarani, é um recurso comum nos escritos de Alencar - e não apenas desse autor em particular, basta observamos românticos como Gonçalves de Magalhães e sua Confederação dos Tamoios, além de outros escritores.

Os paratextos nos permitem ver que Alencar respondeu às críticas que envolveram suas obras, principalmente as indianistas. No caso desses dos Posfácio de Iracema e o prefácio Bênção Paterna, a resposta foi ao português Manuel Joaquim Pinheiro Chagas que, em Novos ensaios críticos, escreveu a respeito da linguagem que era utilizada pelos escritores brasileiros. No Posfácio à $2^{\circ}$ edição de Iracema, Alencar dirigiu-se ao crítico da seguinte forma:

Acusa-nos o Sr. Pinheiro Chagas a nós escritores brasileiros do crime de insurreição contra a gramática da nossa língua comum. Em sua opinião estamos possuídos da mania de tornar o brasileiro uma língua diferente do velho português! Que a tendência, não para a formação de uma nova língua, mas para a transformação profunda do idioma de Portugal, existe no Brasil, é fato incontestável.

[...] Quando povos de uma raça habitam a mesma região, a independência política, por si só, forma sua individualidade. Mas se esses povos vivem em continentes distintos, sob climas diferentes, não se rompem unicamente os vínculos políticos; opera-se também a separação nas idéias, nos sentimentos, nos costumes, e portanto na língua, que é a expressão desses fatos morais e sociais. ${ }^{14}$ 
Em Bênção Paterna, as respostas continuaram direcionadas a Pinheiro Chagas:

Sobretudo compreendam os críticos a missão dos poetas,
escritores e artistas, nesse período especial e ambíguo da
formação de uma nacionalidade. São êstes os operários
incumbidos de polir o talhe e as feições da individualidade
que se vai esboçando no viver do povo.
[... O povo que chupa o caju, a manga, o cambucá e a
jabuticaba, pode falar uma língua com igual pronúncia e o
mesmo espírito do povo que sorve o figo, a pêra, o damasco
e a nêspara? ${ }^{15}$

Nos dois fragmentos acima, Alencar não respondeu ao crítico português apenas em seu nome, mas em nome de autores, poetas e artistas brasileiros. Em seu revide, Alencar justificou o uso da linguagem coloquial por meio da nacionalidade envolvida em questões políticas e naturais - fauna e flora. De fato, a polêmica em torno de uma língua nacional foi comum entre os escritores do período romântico, quando "o problema adquiriu contornos mais definidos" pois escritores - Gonçalves Dias, José de Alencar, Gil Montalverne, Luis José Junqueira Freire - e historiadores - Varnhagen e João Francisco Lisboa - "alinharam-se entre aqueles que defendiam, com maior ou menor ênfase, a diversificação do português do Brasil." Neste contexto, José de Alencar defendeu a criação de seus "neologismos estilísticos" e o uso literário da linguagem coloquial. ${ }^{16}$ Além disso, o uso dos paratextos tinha também como função a "elevação da arte literária, por conceber a ela a dimensão de um grande estilo". ${ }^{17}$

Isso também coincide com a transformação por que passou a erudição histórica. No final do século XVIII e nos primeiros decênios do XIX, observouse o estabelecimento da história racionalista e, especificamente, no começo do século XIX - inicialmente na Alemanha - o aparecimento da crítica histórica e do método erudito. A partir daquele momento, a erudição, no campo histórico, passou a ser essencial. Um exemplo disso foi Leopoldo von Ranke, que trouxe para a história a análise documental, como nos demonstra Georges Lefebvre: "ha sido el primero en utilizar los documentos diplomáticos para escribir la historia de los Estados y de sus relaciones [...] descubrió, utilizo y criticó esos documentos, todo a um mismo tiempo". ${ }^{18}$ Demonstrar o conhecimento por meio de documentos, especialmente, oficiais - ou considerados oficiais, pela erudição do período - aponta uma tendência histórica que influenciou os escritores românticos, principalmente aqueles que se dedicaram aos romances históricos, como é o caso de Alencar. Tal gênero literário possibilitava a comprovação das leituras, do conhecimento e da análise dos documentos utilizados. Esses relatos de erudição apresentaram-se, entre outros, por meio dos já citados paratextos e notas de rodapé. ${ }^{19}$ 
No caso de Alencar, o conhecimento histórico apresentado nas notas não tem apenas como função comprovar os fatos, mas demonstrar uma erudição acerca do período narrado e da própria história nacional, em conformidade com as próprias funções nas notas de rodapé no texto erudito ou literário. Alencar conhece os fatos, os heróis históricos e, principalmente, os autores que escreveram sobre o período. Exemplo disso é o caso de Gabriel Soares de Sousa, utilizado por ele no momento da obra em que descreve o índio Peri:

Um índio - O tipo que descrevemos é inteiramente copiado das observações que se encontram em todos os cronistas. Em um ponto porém variam os escritores: uns dão aos nossos selvagens uma estatura abaixo da regular; outros uma estatura alta. Nesse ponto preferi guiar-me por Gabriel Soares que escreveu em 1580, e que nesse tempo devia conhecer a raça indígena em todo o seu vigor, e não degenerada como se tornou depois. ${ }^{20}$

Por que Alencar escolheu Gabriel Soares de Sousa para basear e legitimar a descrição do "indígena brasileiro", sendo que tais observações se encontram em todos os cronistas? O próprio Alencar respondeu ao afirmar que Sousa, por ter escrito em 1580, deve ter conhecido a raça indígena em "todo o seu vigor", e não "decaída", como se supunha ser o estado da raça em meados do século XIX, ideia expressa, por exemplo, na famosa monografia de Carl Friedrich Philipp von Martius sobre a escrita da história do Brasil. ${ }^{21}$ Porém, o fato de Sousa ter sido um dos primeiros cronistas coloniais a descrever o Brasil não foi determinante. Seu nome foi referência para vários autores que escreveram no século XIX, entre eles, Varnhagen e Gonçalves de Magalhães. Citar Sousa era demonstrar conhecer os autores lidos e analisados pela intelectualidade do período. Nesse sentido, as notas, além de apoiarem as descrições, legitimavam o conhecimento.

Além do caso de $O$ Guarani, em Iracema, as notas de pé de página aumentam consideravelmente (identificamos mais de cem notas) e, em Ubirajara, o autor utiliza sessenta e sete, sendo que algumas ocupam páginas inteiras dedicadas, não apenas à informação, mas à reflexão acerca de temas trabalhados no romance. Por exemplo, uma das notas aborda a puberdade entre as meninas indígenas. Intitulada "A liga vermelha", Alencar não só cita Sousa, Alcide d'Orbigny, André Thevet e Robert Southey, como também arrisca levar o leitor a um debate acerca de questões sociais e comportamentais:

A liga vermelha - Era êste um dos mais curiosos e interessantes ritos dos tupis.

Quando a menina atingia a puberdade, depois de sua purificação, da qual tratam os autores, especialmente 
Orbigny e Thevet, a mãe punha-lhe nas pernas, abaixo do joelho, uma liga de fio de algodão tinta de vermelho, de três dedos de largura, e tecida no próprio lugar de modo que uma vez fechada, não era mais possível tirá-la. Vide Gabriel Soares, cap. 153.

A essa liga chamavam tapacorá, e não a podia trazer senão a virgem, de modo que, se acontecesse quebrar a castidade, havia de rompê-la para que todos conhecessem sua falta. Eis como Gabriel Soares se exprime a êste respeito no cap. 152: "E como o marido lhe leva a flor, é obrigada a noiva à quebrar êstes fios para que seja notório que é feita dona; e ainda que uma moça dessas seja deflorada por quem não seja seu marido, ainda que seja em segrêdo, há de romper os fios de sua virgindade, que de outra maneira cuidará que a leve o diabo, os quais desastres lhes acontecem muitas vêzes, etc." ${ }^{22}$

Depois de apresentar os autores - Orbigny, Thevet e Sousa, citado, nessa nota, como Gabriel Soares - Alencar inicia uma discussão acerca dos costumes e da moralidade indígena, criticando alguns cronistas que, segundo o próprio autor, mal informados, desconheciam a cultura do silvícola: "Em que sociedade civilizada se observa tão profundo respeito pela união conjugal, a ponto de não consentir-se que a mulher decaída conserve o segrêdo de sua falta, e iluda o homem que a busque para espôsa?". ${ }^{23}$ E continua, finalizando, novamente, com Sousa:

Não é possível negar a castidade da mulher tupi; além desse recato da virgindade, prova-a de modo cabal a continência que homens e mulheres guardavam em certas circunstâncias. Assim nenhum homem tinha relações, com e mulher inúbil, nem ela o consentia; o próprio marido não violava essa lei, embora tivesse a esposa em seu poder. Gabriel Soares cit. durante a gravidez e amamentação interrompiase absolutamente o ajuntamento conjugal. (Barlaeus, $2^{\circ}$ edição). ${ }^{24}$

No caso dos romances $O$ Guarani, Iracema e Ubirajara, encontramos também a necessidade de constatação de fatos, personagens, costumes, descrições físicas, dos indígenas e paisagísticas. Tal comprovação pode ser entendida como um dos objetivos do romance histórico, pois a veracidade dos elementos descritos é uma tentativa de mostrar ao leitor, por exemplo, que o índio Peri era um personagem baseado, fielmente, no silvícola que habitou as matas no início da colonização. Por isso a recorrência aos naturalistas e aos viajantes que passaram pelo Brasil colonial. Para o romantismo brasileiro 
oitocentista, o silvícola encarnava, como uma representação do passado, a origem de uma história nacional. Desta forma, o escritor romântico entendia-se como instituidor de um passado imaginado, neste caso, pela literatura.

Analisando outros autores, encontramos essa mesma estreita relação entre história e literatura. Joaquim Manuel de Macedo explorou tal analogia na obra Memórias da Rua do Ouvidor. Além de mencionar dados históricos acerca da cidade do Rio de Janeiro - citando episódios históricos narrados pelo tão lido Baltasar da Silva Lisboa, como a Guerra dos Tamoios - Macedo se autoproclama memorista e historiador: "Salvo o respeito devido à sua atual condição de rica, bela e ufanosa dama, tomo com a minha autoridade de memorista-historiador, e exponho ao público a Rua do Ouvidor em seus cueirinhos de menina recém-nascida e pobre". ${ }^{25}$ Em Alencar, o memoristahistoriador encontra-se em algumas passagens de seus paratextos, como nas Cartas sobre a confederação dos Tamoios, de 1856 que retrata o famoso debate travado, principalmente, entre o Diário do Rio de Janeiro e o Jornal do Comércio, por Alencar, Manoel de Araújo Porto-Alegre, "Sr. Omega" (atribuído a Pinheiro Guimarães), D. Pedro II, entre outros. Na última carta, Alencar define o poeta como historiador:

Mas quando o homem, em vez de uma idéia, escreve um poema; quando da vida do indivíduo se eleva a vida de um povo; quando, ao mesmo tempo historiador do passado e profeta do futuro, ele reconstrói sobre o nada uma geração que desapareceu da face da terra para mostrá-la a posteridade, é preciso que tenha bastante confiança, não só no seu gênio e na sua imaginação, como na palavra que deve fazer surgir esse mundo novo e desconhecido.

Então já não é o poeta que fala; é uma época inteira que exprime pela sua voz as tradições, os fatos e os costumes; é a história, mas a história viva animada, brilhante como o drama, grande e majestosa como tudo que nos aparece através do dúplice véu do tempo e da morte"26.

Tal ideia acerca do poeta/escritor como historiador, permaneceu na primeira edição da Guerra dos mascates (1871). Num pós-escrito da primeira parte, intitulado Nota, Alencar demonstra como o romance histórico deveria ser pautado em fontes do passado e nos processos usados por cientistas naturalistas e cronistas. Uma tarefa, segundo o autor, de árdua composição do passado, uma escrita que não se realiza numa viagem ou mesmo "num canto da mesa de jantar":

Para se descrever a nossa sociedade colonial é necessário reconstruí-la pelo mesmo processo de que usam os naturalistas com os animais antediluvianos. De um osso, êles 
recompõem a carcaça, guiados pela analogia e pela ciência. O escritor que no Brasil tenta o romance histórico, há de cometer antes de tudo essa árdua tarefa de recompor, com os fragmentos catados nos velhos cronistas, a colônia portuguesa da América, tal como ela existiu [...]. ${ }^{27}$

Alencar recompõe o passado através de fragmentos dos textos dos cronistas, indicando uma forma possível de como ele os leu. Ele também demonstra como criou seus próprios discursos sobre a leitura, ao caracterizar o romance - e o papel do literato - como sendo o de um memorista-historiador. Ao fazer isso, ele se insere em um método interpretativo indiciário, que nos permite analogias com as análises de Carlo Ginzburg em Mitos, emblemas e sinais. $^{28}$

Analisando determinados estudos de Giovanni Morelli acerca da pintura italiana que deram origem ao método morelliano - baseado em vestígios e particularidades que poderiam diferenciar as cópias artísticas das originais - Ginzburg apresenta o paradigma indiciário baseado na observação, que se afirmou nas ciências humanas na década de 1870-80, entretanto, com raízes mais antigas. Utilizando a antropologia, o autor demonstra como o historiador pode construir um saber caracterizado pela capacidade de remontar uma realidade não vivenciada diretamente: "Pode-se acrescentar que esses dados são sempre dispostos pelo observador de modo tal a dar lugar a uma seqüência narrativa....". ${ }^{29}$

O paradigma indiciário, mesmo que aponte para uma particularidade - marcas individuais, como no caso da pintura, ou estéticas particulares, no caso da literatura - não abandona a ideia de totalidade, como, por exemplo, nas interpretações textuais, nas quais o texto de uma obra não se identifica apenas com seu suporte, mas, no caso de Alencar, com uma determinação cultural ${ }^{30}$. Nesse sentido, a análise de Ginzburg pode nos apresentar um caminho: observando as afirmações de Alencar em relação à constituição do romance histórico, percebemos um discurso acerca de seu processo de elaboração baseado em fragmentos e suas analogias - e um possível tipo de leitura dos velhos cronistas coloniais.

Em Ubirajara, Alencar deixa mais claro como deveria ser a leitura de cronistas coloniais ou mesmo historiadores e viajantes:

Os historiadores, cronistas e viajantes da primeira época, senão de todo o período colonial, devem ser lidos à luz de uma crítica severa. É indispensável sobretudo escoimar os fatos comprovados das fábulas a que serviram de mote, e das apreciações a que os sujeitavam espíritos acanhados, por demais imbuídos de uma intolerância ríspida. ${ }^{31}$ 
Ubirajara, cuja primeira edição é de 1874 , posterior, portanto, a $O$ Guarani - proporciona alguns rastros para a compreensão das leituras de Alencar. Primeiramente, apresenta algumas impressões de leitura e um possível discurso acerca dela própria quando narra que historiadores, cronistas e viajantes, "devem ser lidos à luz de uma crítica severa". Tal discurso acerca de uma leitura crítica é comum, podendo ser observado desde os primeiros escritos de Alencar com, por exemplo, as Cartas sobre confederação dos Tamoios. Num segundo momento, apresenta a sustentação das leituras que referimos anteriormente: de cronistas, historiadores, viajantes. Antonio Candido - em sua obra $A$ formação da literatura brasileira - ao analisar as discussões travadas entre Franklin Távora e Alencar acerca da Confederação dos Tamoios, indica como a leitura de tal obra estimulou José de Alencar na composição de suas narrativas, principalmente de $O$ Guarani, o primeiro de uma série de romances históricos. ${ }^{32}$

Temos assim duas importantes questões presentes nos paratextos sob análise: por um lado, a relação estreita entre o literato e o historiador, descrita e, possivelmente, vivenciada por Alencar e, por outro, a promoção de um possível tipo de leitura: a leitura crítica. Sobre esta segunda ideia, devemos considerar a recomendação de Alencar aos seus leitores de duas maneiras: primeiramente, como discurso acerca de uma provável leitura e, num segundo momento, como uma possível leitura crítica dos textos que cita. Dessa forma, cabe-nos identificar as rupturas e as permanências, nos discursos encontrados nos escritos de Alencar, acerca da leitura e de suas práticas. Para isso, contamos, entre outras coisas, com indícios alencarianos: as notas de seus romances indianistas e as funções que elas exerceram. Com efeito, a literatura de Alencar procura realizar a perspectiva indiciária, segundo a qual, a leitura dos historiadores, viajantes e outros importantes intelectuais dedicados à descrição do Brasil, fornece indícios, através dos quais, a totalidade natural e cultural de um país em formação pode ser reconstituída. As leituras de Alencar, assim, nos permitem tratar de um problema duplo, colocando-se como um pano de fundo histórico para sua literatura e, ao mesmo tempo, promovendo o romance como gênero literário ligado a um certo realismo de caráter histórico, como foi mencionado acima.

Por outro lado, as notas podem funcionar como um elemento de acesso aos indícios das leituras que o próprio José de Alencar realizou. Primeiramente, as notas são apresentadas como um meio comprobatório de uma realidade idealizada pelo autor, pois "O papel das notas, então, fundamenta-se em fazer com que o leitor absorva precisamente uma apresentação da realidade que se queria ideal". ${ }^{33}$ Além disso, as notas tinham um caráter didático: indicavam a maneira como a obra e as personagens deveriam ser lidas e instruíam o leitor acerca da história nacional, dos costumes indígenas e das imagens da natureza brasileira. 
Alencar empregava as notas no sentido de se mostrar conhecedor da terra que descrevia, por isso o cuidado na organização das mesmas e no desenvolvimento dos comentários presentes, tanto nas notas de pé de página, quanto nos prefácios e pós-escritos. A harmonização da narrativa com esses paratextos seria guiada, segundo Mirhiane Abreu, por um segundo narrador, que baseia suas informações nas fontes documentais disponíveis no século XIX. Ao mesmo tempo, a autora demonstra, confirmando a tendência literária oitocentista, que o escritor utilizou os paratextos como respostas às críticas e as polêmicas literárias do período. ${ }^{34}$

O trabalho de Abreu aponta outras questões acerca das notas, tomadas como uma segunda narrativa de múltiplas funções, o que é plausível numa análise literária. Contudo, a tese não teve como objetivo realizar um estudo específico das leituras de Alencar ou mesmo um exame do discurso acerca dessas leituras. Cabe à História trabalhar essas questões e aprofundar, numa abordagem teórico-metodológica particular, a questão da leitura presente nos diversos escritos alencarianos, como é o caso das notas de pé de página. Nesse sentido, as notas - e os paratextos - devem ser vistos, antes de tudo, como indicações de leituras, resquícios de um leitor oitocentista e como uma possível imposição de um discurso acerca da leitura.

Tendo em vista essa questão, é importante identificarmos as notas de rodapé em outros gêneros literários pelos quais transitou Alencar, como é o caso dos romances urbanos, regionalistas - Diva (1864), Til (1872), O sertanejo (1875) - e em sua autobiografia Como e porque sou romancista (1873), entre outros. Antonio Cândido, em A formação da literatura brasileira, apresentanos algumas definições desses gêneros ou matérias - regionalistas, urbanos e indianistas - presentes no romance. Segundo o autor, o romance brasileiro apresenta três graus de matéria, de acordo com o espaço onde se desenvolve a narrativa: cidade, campo e selva. José de Alencar transitou pelos três, exemplo disso seriam Lucíola, O Sertanejo e $O$ Guarani. Além disso, a diferença entre tais matérias do romance não se definem apenas pelo espaço. No caso dos romances indianistas e regionalistas, as descrições de costumes são essenciais para a classificação: o primeiro dedica-se à descrição de uma população de língua e costumes diferentes do português e do urbano, e o segundo, aproxima esses elementos num contexto mais urbano. ${ }^{35}$

$\mathrm{O}$ recurso às notas assemelha-se nos diferentes gêneros alencarianos, apresentando, muitas vezes, um tom explicativo, como se pode observar, por exemplo, no romance urbano Diva (1864), no qual o autor se utiliza deste recurso para esclarecer o verbo fervilhar:

Fervilhar - É palavra conhecida e usada; é o diminutivo de ferver. Essa propriedade de diminuir a significação dos verbos, como de aumentar pela desinência, é outro privilégio da língua portuguêsa. ${ }^{36}$ 
Além de esclarecer e referenciar, devemos lembrar que as notas de rodapé acompanhavam um gênero literário - no caso o romance - que, durante sua fase inicial, foi associado a "uma leitura frívola e como entretenimento de pessoas desocupadas". ${ }^{37}$ As notas, dessa forma, colaboraram com a instrução do leitor e a legitimação do conhecimento - especialmente no caso do romance histórico - um gênero que estava se estabelecendo e, consequentemente, criando seu público leitor. Essa formação do público fez-se, ao mesmo tempo, por meio da apresentação de características próximas à realidade, como nos demonstra Germana Sales:

O gênero romanesco apresentava em maior ou menor escala traços da vida comum, os que oferecem uma maior aproximação com a realidade nos enredos do romance foram pintadas cenas concernentes à vida íntima familiar, aos ambientes caseiros, situações rotineiras do cotidiano, quadros que expressavam o homem comum nos seus sentimentos de amor, dor, felicidade, rejeição, insegurança $[\ldots] .^{38}$

Mesmo em um romance ambientado no período colonial brasileiro, como é o caso de $O$ Guarani, a verossimilhança é parte essencial da obra, embora o objetivo não fosse apenas o entretenimento, mas a narração de uma particular história brasileira. Desta forma, é comum encontrarmos, nos paratextos alencarianos, algumas contradições. No $O$ Guarani, na nota referente a Peri, intitulada Um índio, Alencar afirma que a descrição realizada é inteiramente copiada das observações de cronistas. Em Como e por quê sou romancista, porém, assegura que o selvagem de $O$ Guarani é um ideal poetizado. Considerando que as duas obras citadas foram escritas em períodos distintos - sendo a última um trabalho diferenciado do escritor, pautado, sobretudo, nas respostas às críticas que sempre acompanharam sua carreira literária - percebemos, nessas colocações, questões importantes, já que o discurso presente em sua autobiografia não pode ser, apenas, entendido como uma resposta às críticas do período, mesmo confirmando-se a idealização do índio em sua obra $O$ Guarani.

Esse debate aponta para duas questões importantes para a apreensão da apropriação dos textos lidos para compor O Guarani e que serão desenvolvidas no decorrer deste trabalho: a prática de leitura e seu discurso. Ambos, são encontrados nos escritos alencarianos e nas análises da História da leitura. A primeira diz respeito à maneira como Alencar teria lido e se apropriado de determinadas obras, assimilando e recriando, ou não, elementos fundamentais para o indígena em $O$ Guarani. Para Roger Chartier, tal perspectiva histórica - além de possibilitar novas abordagens para fontes constantemente utilizadas pela historiografia - deve ser uma "reconstituição das variações nas práticas", 
e não apenas uma história de textos e de livros. Nesse sentido, o historiador deve atentar para a utilização diferenciada e oposta de um mesmo texto, de uma mesma ideia e não mais percebê-lo como uma única e universal apropriação: "As práticas de apropriação sempre criam usos ou representações muito pouco redutíveis aos desejos ou às intenções daqueles que produzem os discursos e as normas". ${ }^{39}$

Mas como perceber essas apropriações de leituras? Além das indicações dos livros lidos, dos relatos de impressão de leituras que nos dão pistas acerca da prática e do discurso que envolvem a leitura - alguns já citados anteriormente - temos a própria obra: fruto das leituras, dos discursos nacionalistas e das estéticas românticas. O Guarani apresenta a união de todos esses procedimentos, como também, a descrição de possíveis dados que surgiram por meio da leitura.

A segunda questão, o discurso sobre a leitura, pode ser compreendido como uma narrativa acerca dessa prática, não envolvendo, dessa forma, o processo de criação da imagem do silvícola, mas propagando outros elementos: local, postura e instrução de leitura de determinados autores.

Anota Um índio, demonstra essas duas questões. De um lado, aponta uma possível mudança na prática de leitura de nosso leitor, pois, se nos paratextos de O Guarani, Alencar apresenta uma leitura supostamente "passiva" dos viajantes e cronistas, na Advertência, em Ubirajara, exalta a necessidade de uma leitura "crítica" em relação aos textos citados em suas obras indianistas. Ubirajara foi o terceiro e último romance indianista de Alencar. Observando as notas, o autor, ao contrário do que acontece com os anteriores, O Guarani e Iracema, dialoga com maior intensidade com seu leitor que, provavelmente, tenha lido os dois primeiros livros. É comum, nesse sentido, Alencar demonstrar-se mais crítico em relação às fontes utilizadas e aos autores citados, sendo que, muitos deles, foram referenciados nos dois textos indianistas anteriores.

Dito isso, podemos identificar essas descrições acerca da leitura numa outra esfera que não seja a mudança na prática da leitura propriamente dita. Mesmo porque, apenas a análise das notas não possibilita tal conclusão. Tais citações podem apontar uma alteração no discurso alencariano acerca da leitura - que, em O Guarani, apresentou-se, pelo menos nas notas, de forma passiva e, em Ubirajara, é propagado de maneira crítica - e não numa possível variação dessa prática. Pode-se considerar, do mesmo modo, a formação contínua do público leitor oitocentista, que esperava de seu autor, não apenas a apresentação da obra em questão, como também, orientação acerca da história a ser lida, o que estabelecia um vínculo entre autor e leitor. ${ }^{40}$ Era uma relação tão estreita que o autor se sentia à vontade para sugerir até o lugar da leitura, como podemos observar nesse trecho selecionado do Prólogo da primeira edição de Iracema intitulado Meu amigo: 
O livro é cearense. Foi imaginado aí, na limpidez desse céu de cristalino azul, e depois vazado no coração cheio das recordações vivazes de uma imaginação virgem. Escrevi-o para ser lido lá, na varanda da casa rústica ou na fresca sombra do pomar, ao doce embalo da rede, entre os múrmuros do vento que crepita na areia ou farfalha nas palmas dos coqueiros. ${ }^{41}$

Esse fragmento sugere um local de leitura, um espaço onde seria melhor essa prática cultural como, por exemplo, "ao doce embalo da rede". Entretanto, o nosso leitor Alencar, deixou, em alguns trechos de seus textos, outros "espaços de leitura". ${ }^{42}$

O que as notas de rodapé e outros paratextos alencarianos nos fornecem, portanto, é a possibilidade de vermos a "materialidade do texto" e a "historicidade do leitor". ${ }^{43}$ José de Alencar utilizou as notas de rodapé para moldar e defender suas posições quanto à nacionalidade brasileira - na língua, na literatura e na história, recorrendo àquilo que, coletivamente, elegeu-se como "historiografia brasileira do século XVIII e XIX".

\section{NOTAS}

${ }^{1}$ GRAFTON, Anthony. As origens trágicas da erudição: pequeno tratado sobre a nota de rodapé. Campinas: Papirus, 1998. p. 17.

${ }^{2}$ CHARTIER, Roger. Forms and meanings. Philadelphia: University of Philadelphia Press, 1995.

3 DELMAS, Ana Carolina Galante. "Do mais fiel e humilde vassalo": uma análise das dedicatórias impressas no Brasil joanino. Rio de Janeiro. UERJ. Mestrado em História. 2008.

${ }^{4}$ DARNTON, Robert. História da leitura. In: BURKE, Peter. (Org.). A escrita da história, novas perspectivas. São Paulo: Unesp, 1992. p. 199-236.

${ }^{5}$ GRAFTON, op. cit., p. 18.

${ }^{6}$ Ibidem, p. 24-25.

7 Ibidem, p. 30.

${ }^{8}$ MOLLIER, Jean-Yves; CACHIN, Marie-Françoise. A continent of texts: Europe 1800-1890. In: ELIOT, Simon; ROSE, Jonathan, eds. A companion to the History of the Book. London: Wiley-Blackwell, 2010. p. 303-328.

${ }^{9}$ GRAFTON, op. cit., p. 36.

${ }^{10}$ ABREU, Mirhiane Mendes. Ao pé da página: a dupla narrativa em José de Alencar. Campinas, Mercado das Letras, 2011. p. 171.

${ }^{11}$ ALENCAR, José de. O Guarani. São Paulo: Melhoramentos, s./d, p. 7.

${ }^{12}$ Ibidem, p. 503.

${ }^{13}$ DARNTON, op. cit., p. 208. 
${ }^{14}$ ALENCAR, José de. Pósfácio à $2^{\circ}$ edição de Iracema. In: TELLES, Gilberto Mendonça etc tal (Org.). Prefácios de Romances brasileiros. Porto Alegre: Acadêmica, 1986. p. 95-111.

${ }^{15}$ ALENCAR, José de. Benção Paterna. In: Sonhos D'Ouro. São Paulo: Melhoramentos, [19-]. p. 5-13.

${ }^{16}$ DE LUCA, Tania Regina. A Revista do Brasil: um diagnóstico para a (N)ação. São Paulo: Fundação Editora da Unesp, 1999. p. 243.

${ }^{17}$ ABREU, op. cit. p. 171.

${ }^{18}$ LEFEBVRE, G. El nacimiento de la historiografia moderna. Barcelona: Ediciones Martínez Roca [19-]. p.276.

${ }^{19}$ GRAFTON, Anthony. The Footnote from De Thou to Ranke. History and Theory, v. 33, n. 4, Theme Issue 33: Proof and Persuasion in History. dec., 1994. p. 53-76.

${ }^{20}$ ALENCAR, op. cit., p. 504.

${ }^{21}$ MARTIUS, Carlos Frederico Von. Como se deve escrever a história do Brasil. Bolletim do Instituto Histórico e Geográfico Brasileiro, n. 24, janeiro de 1845.

${ }^{22}$ ALENCAR, José de. Ubirajara. São Paulo: Piratininga, [19-]. p. 193.

${ }^{23}$ Ibidem.

${ }^{24}$ Ibidem.

${ }^{25}$ MACEDO, Joaquim Manuel de. Memórias da Rua do Ouvidor. São Paulo: Saraiva, [19-]. Coleção Saraiva. p. 2.

${ }^{26}$ ALENCAR, José de. Última carta. In: A polêmica sobre "A Confederação dos Tamoios". São Paulo: Faculdade de Filosofia, Ciências e Letras da Universidade de São Paulo, 1953. Coleção Textos e Documentos. p. 33-34.

${ }^{27}$ ALENCAR, José de. Guerra dos mascates. São Paulo: Edições Melhoramentos, [19-]. p. 111.

${ }^{28}$ GINZBURG, Carlo. Mitos, emblemas e sinais. São Paulo: Companhia das Letras, 1991.

${ }^{29}$ Ibidem, p.151-152.

${ }^{30}$ Ibidem, p. 157-178.

${ }^{31}$ ALENCAR, José de. Ubirajara. São Paulo: Piratininga, [19-]. p. 115.

${ }^{32}$ CANDIDO, Antônio. Formação da Literatura Brasileira (momentos decisivos). v. 2 (18361880). Martins: São Paulo, 1971.

${ }^{33}$ ABREU, op. cit., p. 57.

${ }^{34}$ Ibidem, p. 80-156.

${ }^{35}$ CANDIDO, op. cit., p. 113-116.

${ }^{36}$ ALENCAR, José de. Diva. São Paulo: Melhoramentos, [19-]. p. 162 .

${ }^{37}$ SALES, Germana Maria Araújo. Palavra e sedução: uma leitura dos prefácios oitocentistas (1826-1881). Tese (Doutorado em Teoria e História Literária), Unicamp, Campinas, 2003, p. 81.

${ }^{38}$ Ibidem, p. 87

${ }^{39}$ CHARTIER, Roger. Textos, impressões e leituras. In: HUNT, Lynn. A nova história cultural. 
São Paulo: Martins Fontes, 1992. p. 232-233.

${ }^{40}$ A respeito desse tema indicamos a obra, já citada, de Germana Sales, especificamente o capítulo "Duas palavras entre dois amores: o autor e o leitor".

${ }^{41}$ ALENCAR, José de. Iracema, São Paulo: Piratininga, [19-]. p. 7-8.

${ }^{42}$ SALES, op. cit.

${ }^{43}$ CHARTIER, Roger. A história ou a leitura do tempo. Belo Horizonte: Autêntica, 2009. p. 38.

Artigo recebido em setembro de 2012. Aceito em março de 2013. 